Pacific Journal of Mathematics

ON UNITS OF PURE QUARTIC NUMBER FIELDS 


\title{
ON UNITS OF PURE QUARTIC NUMBER FIELDS
}

\author{
AKIRA ENDÔ
}

Let $K=Q\left(\sqrt[4]{D^{4} \pm d}\right)$ be a pure quartic number field, where $D$ and $d$ are natural numbers such that $d$ divides $D^{3}$ and $d$ is fourth power free. Then $\varepsilon= \pm\left(\sqrt[4]{D^{4} \pm d}+D\right) /\left(\sqrt[4]{D^{4} \pm d}-D\right)$ is a unit of $K$ whose relative norm to the quadratic subfield of $K$ is 1 . We consider the condition for $\varepsilon$ to be a member of a system of fundamental units of $K$.

1. Introduction. There have been many investigations concerning units of pure extensions of the rational number field of degree $n>2$ generated by $\sqrt[n]{D^{n} \pm d}$, where $D$ and $d$ are natural numbers satisfying certain conditions ([2], [4], [7], [9], etc.). In general, suppose $d$ divides $D^{n-1}$ or, if $n$ is a power of a prime number $p, d$ divides $p D^{n-1}$. Then the numbers

$$
\varepsilon_{k}=\frac{\omega^{k}-D^{k}}{(\omega-D)^{k}}, \quad \omega=\sqrt[n]{D^{n} \pm d},
$$

where $k$ runs over all the divisors of $n$ except 1, are units and, moreover, independent in the real algebraic number field generated by $\omega[1],[2],[4]$. (The proof of independence of the $\varepsilon_{k}$ 's given by Halter-Koch and Stender [4] is incomplete. But the proof can be corrected by a slight modification.) When $n=3,4$ or 6 , the number of such divisors is equal to the rank of the unit group of the field $Q(\omega)$, where $Q$ denotes the rational number field. In this paper we shall treat these units in the case $n=4$.

The following result is established by Stender [8], [9]:

Let $D$ and $d$ be two natural numbers such that $d \mid 2 D^{3}$, and put $A=D^{4} \pm d$ and $\omega=\sqrt[4]{A}$. Suppose that $d$ is fourth power free and $A / d$ or $2 A / d$ is square free, according as $d \mid D^{3}$ or $d \mid 2 D^{3}$. Then

$$
\varepsilon_{2}= \pm \frac{\omega+D}{\omega-D} \quad \text { and } \quad \varepsilon_{4}= \begin{cases}\frac{d}{(\omega-D)^{4}} & \text { if } d \text { is not a square, } \\ \frac{\sqrt{d}}{(\omega-D)^{2}} & \text { if } d \text { is a square and } d \neq 1, \\ \pm \frac{1}{\omega-D} & \text { if } d=1\end{cases}
$$


form a system of fundamental units of $Q(\omega)$, except for the three cases $\omega^{k}=8=2^{4}-8, \omega^{4}=12=2^{4}-4$ and $\omega^{4}=20=2^{4}+4$.

In this paper we shall remove the above assumption on $A / d$, and study the properties of $\varepsilon_{2}$.

2. Known facts. First, we state a few known facts on units of a pure quartic number field. Let $A$ be a natural number which is fourth power free; then we can write $A=f g^{2} h^{3}$ with natural numbers $f, g, h$ such that $f g h$ is square free. We suppose $f h \neq 1$. Then the pure quartic number field $K=Q(\sqrt[4]{A})$ generated by $\sqrt[4]{A}$ contains a unique quadratic subfield, namely $Q(\sqrt{f h})$. Any integer $\alpha$ of $K$ is of the form

$$
\alpha=\frac{1}{k}\left(x_{0}+x_{1} \sqrt[4]{f g^{2} h^{3}}+x_{2} \sqrt{f h}+x_{3} \sqrt[4]{f^{3} g^{2} h}\right)
$$

with rational integers $x_{0}, x_{1}, x_{2}, x_{3}$ and $k=1,2$ or 4 , and its conjugate relative to $Q(\sqrt{f h})$ is

$$
\alpha^{\prime}=\frac{1}{k}\left(x_{0}-x_{1} \sqrt[4]{f g^{2} h^{3}}+x_{2} \sqrt{f h}-x_{3} \sqrt[4]{f^{3} g^{2} h}\right)
$$

Now let $\varepsilon_{0}>1$ be the smallest unit of $K$ such that $\varepsilon_{0} \varepsilon_{0}^{\prime}=1$, and $\varepsilon^{*}>0$ the fundamental unit of $Q(\sqrt{f h})$.

LEMMA 1 ([5], [6]). $\varepsilon_{0}$ and $\varepsilon^{*}$ or $\varepsilon_{0}$ and $\sqrt{\varepsilon^{*} \varepsilon_{0}}$ form a system of fundamental units of $K$; the former case occurs if and only if neither $\varepsilon^{*}$ nor $-\varepsilon^{*}$ is the norm of a unit of $K$ to $Q(\sqrt{f h})$.

In any case, $\varepsilon_{0}$ appears as a member of a system of fundamental units of $K$. The following result will aid in determining $\varepsilon_{0}$ :

LeMma 2 ([6]). Let $A_{1}$ and $A_{2}$ be two positive rational integers such that $Q\left(\sqrt[4]{A_{1} A_{2}^{3}}\right)=Q(\sqrt[4]{A})$. Then the indeterminate equation

$$
A_{1} x^{4}-A_{2} y^{4}= \pm C \quad \text { with } C=1,2,4
$$

has at most one positive integer solution. If $(a, b)$ is a positive integer solution of this equation, then $\pm\left(a \sqrt[4]{A_{1}}+b \sqrt[4]{A_{2}}\right) /\left(a \sqrt[4]{A_{1}}-b \sqrt[4]{A_{2}}\right)$ is a unit of $Q(\sqrt[4]{A})$ whose relative norm to $Q(\sqrt{A})$ is 1 , and furthermore is equal to $\varepsilon_{0}$ or $\varepsilon_{0}^{2}$ with the only two exceptions $x^{4}-5 y^{4}=1$ and $4 x^{4}-3 y^{4}=1$. 
3. Theorems. From now on, we take $A$ so that $K=Q(\sqrt[4]{A})=$ $Q\left(\sqrt[4]{D^{4} \pm d}\right)$, and suppose that $d \mid D^{3}$ and $d$ is fourth power free. Then there is a natural number $u$ satisfying

$$
u^{4} A=D^{4} \pm d .
$$

We write $d=d_{1} d_{2}^{2} d_{3}^{3}$ with natural numbers $d_{1}, d_{2}, d_{3}$ such that $d_{1} d_{2} d_{3}$ is square free. It is easy to see that $d_{1}\left|f, d_{2}\right| g, d_{3} \mid h$.

Now we write $\sqrt[4]{A}=\omega$ and put

$$
\varepsilon_{2}= \pm \frac{u \omega+D}{u \omega-D}
$$

which is a unit of $K$. In the special case where $u=1$ and $A / d$ is square free, i.e. $g=d_{2}, h=d_{3}$, as already mentioned in the introduction, Stender's result [8], [9] states that $\varepsilon_{2}$ is contained in a system of fundamental units of $K$ with the exception of three cases. Moreover [3],

$$
\varepsilon^{*}= \begin{cases}\frac{d}{\left(\omega^{2}-D^{2}\right)^{2}}, & d_{1} d_{3} \neq 1, \\ \pm \frac{\sqrt{d}}{\omega^{2}-D^{2}}, & d=d_{2}^{2},\end{cases}
$$

and $\pm \varepsilon^{*}$ are the norms of no unit of $K$ to $Q(\sqrt{f h})$.

Since

$$
Q\left(\sqrt[4]{D^{4} \pm d}\right)=Q\left(\sqrt[4]{D^{\prime 4} \mp d^{\prime}}\right)
$$

where $D^{\prime}=u\left(f / d_{1}\right)\left(g / d_{2}\right)\left(h / d_{3}\right), d^{\prime}=\left(f / d_{1}\right)^{3}\left(g / d_{2}\right)^{2}\left(h / d_{3}\right), d^{\prime} \mid D^{\prime 3}$ and $d^{\prime}$ is fourth power free, we treat below exclusively the plus case, i.e. $u^{4} A=D^{4}+d$. We write simply $\varepsilon_{2}=\varepsilon$ :

$$
\varepsilon=\frac{u \omega+D}{u \omega-D}=\frac{1}{d}\left(2 D^{4}+d+2 D^{3} u \omega+2 D^{2} u^{2} \omega^{2}+2 D u^{3} \omega^{3}\right) .
$$

Obviously $\varepsilon \varepsilon^{\prime}=1$. We then consider whether there exists a unit $\eta$ of $K$ such that $\eta \eta^{\prime}=1$ and $\varepsilon=\eta^{2}$.

Let

$$
\eta=\frac{1}{k}\left(x_{0}+x_{1} \sqrt[4]{f g^{2} h^{3}}+x_{2} \sqrt{f h}+x_{3} \sqrt[4]{f^{3} g^{2} h}\right)
$$

be a unit of $K$ with $\eta \eta^{\prime}=1$. Then

$$
x_{0}^{2}+x_{2}^{2} f h-2 x_{1} x_{3} f g h=k^{2},
$$




$$
x_{1}^{2} g h+x_{3}^{2} f g-2 x_{0} x_{2}=0,
$$

and

$$
\begin{aligned}
\eta^{2}=\frac{1}{k^{2}} & \left(x_{0}^{2}+x_{1}^{2} f h+2 x_{1} x_{3} f g h+2\left(x_{0} x_{1}+x_{2} x_{3} f\right) \sqrt[4]{f^{2} h^{3}}\right. \\
& \left.+\left(x_{1}^{2} g h+x_{3}^{2} f g+2 x_{0} x_{2}\right) \sqrt{f h}+2\left(x_{0} x_{3}+x_{1} x_{2} h\right) \sqrt[4]{f^{3} g^{2} h}\right)
\end{aligned}
$$

Hence (1) and (2) imply that $\varepsilon=\eta^{2}$ if and only if

$$
\begin{gathered}
\frac{D^{4}}{d}=\frac{2}{k^{2}} x_{1} x_{3} f g h=\frac{1}{k^{2}}\left(x_{0}^{2}+x_{2}^{2} f h\right)-1, \\
\frac{D^{3}}{d} u=\frac{1}{k^{2}}\left(x_{0} x_{1}+x_{2} x_{3} f\right), \\
\frac{D^{2}}{d} u^{2} g h=\frac{2}{k^{2}} x_{0} x_{2}=\frac{1}{k^{2}}\left(x_{1}^{2} g h+x_{3}^{2} f g\right), \\
\frac{D}{d} u^{3} g h^{2}=\frac{1}{k^{2}}\left(x_{0} x_{3}+x_{1} x_{2} h\right) .
\end{gathered}
$$

From (3)-(6) we have

$$
2 x_{0} x_{2}\left(x_{0} x_{1}+x_{2} x_{3} f\right) h=2 x_{1} x_{3} f g h\left(x_{0} x_{3}+x_{1} x_{2} h\right) .
$$

It easily follows from this, together with (2), that

$$
\left(x_{0} x_{1}-x_{2} x_{3} f\right)\left(x_{1}^{2} h-x_{3}^{2} f\right)=0,
$$

from which, as $f h \neq 1$ is not a square,

$$
x_{0} x_{1}=x_{2} x_{3} f \text {. }
$$

REMARK 1. It is easily shwon that in the above situation the following facts hold:

$$
\begin{array}{ll}
k=1 & \text { if } 4|d, 2| f h \text { or } 2 \nmid f g h, \\
k=2 & \text { if } 2 \nmid d \text { and } 2 \mid g .
\end{array}
$$

We prove here the following:

THEOREM 1. Notations being as above, suppose that $u^{4} A=D^{4}+d$ and $A \neq 5^{3}, 2^{2} 3^{3}$. Then $\varepsilon=\varepsilon_{0}$ or $\varepsilon_{0}^{2}$, and moreover $\varepsilon=\varepsilon_{0}^{2}$ if and only if $A=d$ or $4 d$ and either $2\left(u^{2}+\sqrt{d / A}\right)$ or $2\left(u^{2}-\sqrt{d / A}\right)$ is a square. 
Proof. It follows from Lemma 2 that $\varepsilon=\varepsilon_{0}$ or $\varepsilon_{0}^{2}$. Suppose that $\varepsilon=\eta^{2}$ with $\eta \eta^{\prime}=1$ as above. Then from (3) we have

$$
u^{4} A=u^{4} f g^{2} h^{3}=D^{4}+d=\frac{2}{k^{2}} x_{1} x_{3} f g h d+d .
$$

This implies $A=d$ or $4 d$ because $d_{1}\left|f, d_{2}\right| g, d_{3} \mid h$, and if $2 \mid f h, k=1$ by Remark 1. Furthermore, from (3)-(7) we obtain

$$
x_{1}=\frac{k^{2} D^{3} u}{2 d} \frac{1}{x_{0}}, \quad x_{2}=\frac{k^{2} D^{2} u^{2} g h}{2 d} \frac{1}{x_{0}}, \quad x_{3}=\frac{D}{u f g h} x_{0},
$$

and

$$
\frac{D}{d} u^{3} g h^{2}=\frac{1}{k^{2}}\left(\frac{D}{u f g h} x_{0}^{2}+\frac{k^{4} D^{5} u^{3} g h}{4 d^{2}} \frac{1}{x_{0}^{2}}\right) .
$$

From the last equation we have

$$
\begin{aligned}
0 & =x_{0}^{4}-\frac{k^{2} u^{4} A}{d} x_{0}^{2}+\frac{k^{4} u^{4} D^{4} A}{4 d^{2}} \\
& = \begin{cases}\left(x_{0}^{2}-\frac{k^{2} u^{2}\left(u^{2}+1\right)}{2}\right)\left(x^{2}-\frac{k^{2} u^{2}\left(u^{2}-1\right)}{2}\right), & A=d, \\
\left(x_{0}^{2}-k^{2} u^{2}\left(2 u^{2}+1\right)\right)\left(x_{0}^{2}-k^{2} u^{2}\left(2 u^{2}-1\right)\right), & A=4 d .\end{cases}
\end{aligned}
$$

Since $x_{0}$ is a rational integer, $\left(u^{2} \pm 1\right) / 2$ or $2 u^{2} \pm 1$ must be a square, according as $A=d$ or $A=4 d$. Conversely, if these conditions are satisfied, then

$$
x_{0}=k u v, \quad x_{1}=\frac{k D^{3}}{2 d} \frac{1}{v}, \quad x_{2}=\frac{k D^{2} u g h}{2 d} \frac{1}{v}, \quad x_{3}=\frac{k D}{f g h} v,
$$

where

$$
v= \begin{cases}\sqrt{\frac{u^{2} \pm 1}{2}}, & A=d, \\ \sqrt{2 u^{2} \pm 1}, & A=4 d,\end{cases}
$$

satisfy conditions (1)-(6). Thus the theorem follows.

Remark 2. In the above theorem, $u \neq 1$ if $A=d$. Since the fundamental unit of the real quadratic number field $Q(\sqrt{2})$ is $1+\sqrt{2}$, the natural numbers $u$ such that $\left(u^{2} \pm 1\right) / 2$ is a square are given by $u$ $+\sqrt{u^{2}+1}=(1+\sqrt{2})^{2 l+1}$ or $u+\sqrt{u^{2}-1}=(1+\sqrt{2})^{2 l}$ for some $l \geq 1$. 
Moreover, the natural numbers $u$ such that $2 u^{2} \pm 1$ is a square are given by $\sqrt{2 u^{2}+1}+u \sqrt{2}=(1+\sqrt{2})^{2 l}$ or $\sqrt{2 u^{2}-1}+u \sqrt{2}=(1+\sqrt{2})^{2 l-1}$ for some $l \geq 1$.

In the minus case we have the following:

Theorem 2. Suppose $u^{4} A=D^{4}-d$ and $A \neq 5,2^{2} 3$. Then $\varepsilon=\varepsilon_{0}$ or $\varepsilon_{0}^{2}$, and $\varepsilon=\varepsilon_{0}^{2}$ if and only if $d=1$ or 4 and either $2\left(D^{2}+\sqrt{d}\right)$ or $2\left(D^{2}-\sqrt{d}\right)$ is a square.

Proof. Immediate from Theorem 1 and the remark at the beginning of this section.

REMARK 3. In the above theorem, $D \neq 1$ if $d=1$. The natural numbers $D$ such that $D^{2} / 2 \pm 1$ is a square are given by $\sqrt{2\left(D^{2}+2\right)}+$ $D \sqrt{2}=2(1+\sqrt{2})^{2 l}$ or $\sqrt{2\left(D^{2}-2\right)}+D \sqrt{2}=2(1+\sqrt{2})^{2 l-1}$ for some $l \geq 1$.

Corollary ([9]). If $A=D^{4} \pm d$ and $A / d$ is square free, there exists no unit $\eta$ of $K$ such that $\eta \eta^{\prime}=1$ and $\varepsilon=\eta^{2}$, with the single exception of $A=12=2^{4}-4$.

Proof. By Theorem 1 such a unit cannot exist in the plus case, and hence Theorem 2 shows that $d=1$ or 4 . Then, from the assumption, we have $A=4 f=D^{4}-d=12$, namely $D=2, d=4$, which gives the only exception stated above.

Remark 4. Stender [10] has obtained some sufficient conditions for $\varepsilon=\varepsilon_{0}$, which can also be deduced from Theorems 1 and 2 .

\section{REFERENCES}

[1] L. Bernstein, Der Hasse-Bernsteinsche Einheitensatz für den verallgemeinerten JacobiPerronschen Algorithmus, Abh. Math. Sem. Univ. Hamburg, 43 (1975), 11-20.

[2] L. Bernstein und H. Hasse, Einheltenberechnung mittels des Jacobi-Perronschen Algorithmus, J. Reine Angew. Math., 218 (1965), 51-69.

[3] G. Degert, Über die Bestimmung der Grundeinheit gewisser reell-quadratischer Zahlkörper, Abh. Math. Sem. Univ. Hamburg, 22 (1958), 92-97.

[4] F. Halter-Koch und H.-J. Stender, Unabhänglge Einheiten für die Körper $K=$ $Q\left(\sqrt[n]{D^{n} \pm d}\right)$ mit $d \mid D^{n}$, Abh. Math. Sem. Univ. Hamburg, 42 (1974), 33-40.

[5] W. Ljunggren, Über die Lösung einiger unbestimmten Gleichungen vierten Grades, Avh. Norske Vid.-Akad. Oslo (I), 1934 No. 14, 1-35. 
[6] __ Einige Eigenschaften der Einheiten reeller quadratischer und rein-biquadratischer Zahlkörper mit Anwendung auf die Lösung einer Klasse unbestimmter Gleichungen vierten Grades, Skr. Norske Vid.-Akad. Oslo (I), 1936 No. 12, 1-73.

[7] R. J. Rudman, On the fundamental unit of a purely cubic field, Pacific J. Math., 46 (1973), 253-256.

[8] H.-J. Stenderr, Grundeinheiten für einige unendliche Klassen reiner biquadratischer Zahlkörper mit einer Anwendung auf die diophantische Gleichung $x^{4}-a y^{4}= \pm c$ ( $c=1,2$, 4 oder 8), J. Reine Angew. Math., 264 (1973), 207-220.

[9] Eine Formel für Grundeinheiten in reinen algebraischen Zahlkörpern dritten, vierten und sechsten Grades, J. Number Theory, 7 (1975), 235-250.

[10] __ Lösbare Gleichungen $a x^{n}-b y^{n}=c$ und Grundeinheiten für einige algebraische Zahlkörper vom Grade $n=3,4,6$, J. Reine Angew. Math., 290 (1977), 24-62.

Received April 2, 1981 and in revised form April 28, 1982.

KUMAMOTO UNIVERSITY

KUMAMOTO, JAPAN 



\title{
PACIFIC JOURNAL OF MATHEMATICS EDITORS
}

\author{
Donald BabBitT (Managing Editor) \\ University of California \\ Los Angeles, CA 90024 \\ Hugo RossI \\ University of Utah \\ Salt Lake City, UT 84112 \\ C. C. Moore and Arthur Ogus \\ University of California \\ Berkeley, CA 94720
}

J. DugundiI

Department of Mathematics

University of Southern California

Los Angeles, CA 90089-1113

R. FinN and H. SAMELSON

Stanford University

Stanford, CA 94305

\section{ASSOCIATE EDITORS}
R. ARENS
E. F. BECKENBACH
B. H. NeUmanN
F. WOLF
K. YosHida
(1906-1982)

\section{SUPPORTING INSTITUTIONS}

\author{
UNIVERSITY OF ARIZONA \\ UNIVERSITY OF BRITISH COLUMBIA \\ CALIFORNIA INSTITUTE OF TECHNOLOGY \\ UNIVERSITY OF CALIFORNIA \\ MONTANA STATE UNIVERSITY \\ UNIVERSITY OF NEVADA, RENO \\ NEW MEXICO STATE UNIVERSITY \\ OREGON STATE UNIVERSITY
}

\author{
UNIVERSITY OF OREGON \\ UNIVERSITY OF SOUTHERN CALIFORNIA \\ STANFORD UNIVERSITY \\ UNIVERSITY OF HAWAII \\ UNIVERSITY OF TOKYO \\ UNIVERSITY OF UTAH \\ WASHINGTON STATE UNIVERSITY \\ UNIVERSITY OF WASHINGTON
}

The Supporting Institutions listed above contribute to the cost of publication of this Journal, but they are not owners or publishers and have no responsibility for its content or policies.

Mathematical papers intended for publication in the Pacific Journal of Mathematics should be in typed form or offset-reproduced (not dittoed), double spaced with large margins. Please do not use built up fractions in the text of the manuscript. However, you may use them in the displayed equations. Underline Greek letters in red, German in green, and script in blue. The first paragraph must be capable of being used separately as a synopsis of the entire paper. In particular it should contain no bibliographic references. Please propose a heading for the odd numbered pages of less than 35 characters. Manuscripts, in triplicate, may be sent to any one of the editors. Please classify according to the scheme of Math. Reviews, Index to Vol. 39. Supply name and address of author to whom proofs should be sent. All other communications should be addressed to the managing editor, or Elaine Barth, University of California, Los Angeles, California 90024.

There are page-charges associated with articles appearing in the Pacific Journal of Mathematics. These charges are expected to be paid by the author's University, Government Agency or Company. If the author or authors do not have access to such Institutional support these charges are waived. Single authors will receive 50 free reprints; joint authors will receive a total of 100 free reprints. Additional copies may be obtained at cost in multiples of 50 .

The Pacific Journal of Mathematics is issued monthly as of January 1966. Regular subscription rate: $\$ 132.00$ a year (6 Vol., 12 issues). Special rate: $\$ 66.00$ a year to individual members of supporting institutions.

Subscriptions, orders for numbers issued in the last three calendar years, and changes of address should be sent to Pacific Journal of Mathematics, P.O. Box 969, Carmel Valley, CA 93924, U.S.A. Old back numbers obtainable from Kraus Periodicals Co., Route 100, Millwood, NY 10546.

The Pacific Journal of Mathematics ISSN $0030-8730$ is published monthly by the Pacific Journal of Mathematics at P.O. Box 969, Carmel Valley, CA 93924. Application to mail at Second-class postage rates is pending at Carmel Valley, California, and additional mailing offices. Postmaster: Send address changes to Pacific Journal of Mathematics, P. O. Box 969, Carmel Valley, CA 93924.

PUBLISHED BY PACIFIC JOURNAL OF MATHEMATICS, A NON-PROFIT CORPORATION

Copyright $\odot 1983$ by Pacific Journal of Mathematics 


\section{Pacific Journal of Mathematics}

Vol. 109, No. $2 \quad$ June, 1983

Tibor Bisztriczky, On the singularities of almost-simple plane curves . . . . 257

Peter B. Borwein, On Sylvester's problem and Haar spaces .............. 275

Emilio Bujalance, Cyclic groups of automorphisms of compact nonorientable Klein surfaces without boundary ............... 279

Robert Jay Daverman and John J. Walsh, Acyclic decompositions of

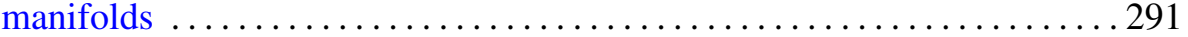

Lester Eli Dubins, Bernstein-like polynomial approximation in higher

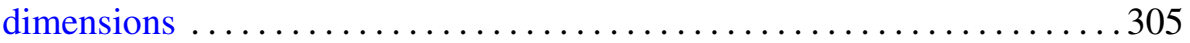

Allan L. Edelson and Jerry Dee Schuur, Nonoscillatory solutions of

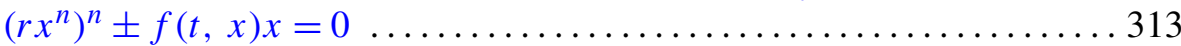

Akira Endô, On units of pure quartic number fields ................. 327

Hector O. Fattorini, A note on fractional derivatives of semigroups and

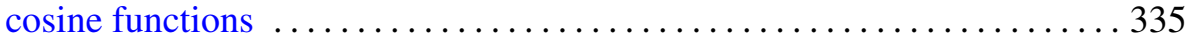

Ronald Fintushel and Peter Sie Pao, Circle actions on homotopy spheres with codimension 4 fixed point set ........................ 349

Stephen Michael Gagola, Jr., Characters vanishing on all but two

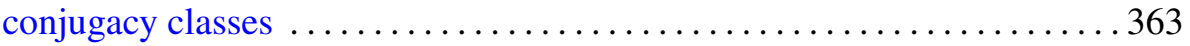

Saverio Giulini, Singular characters and their $L^{p}$ norms on classical Lie

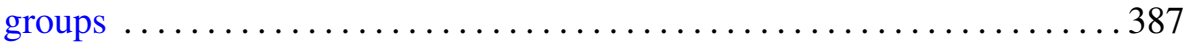

Willy Govaerts, Locally convex spaces of non-Archimedean valued continuous functions

Wu-Chung Hsiang and Bjørn Jahren, A remark on the isotopy classes of diffeomorphisms of lens spaces $\ldots . \ldots \ldots \ldots \ldots \ldots$

Hae Soo Oh, Compact connected Lie groups acting on simply connected 4-manifolds

Frank Okoh and Frank A. Zorzitto, Subsystems of the polynomial system

Knut Øyma, An interpolation theorem for $H_{E}^{\infty}$

Nikolaos S. Papageorgiou, Nonsmooth analysis on partially ordered vector spaces. II. Nonconvex case, Clarke's theory ........ 